\title{
Exploring Wicked Problems and Challenging Status Quo Thinking Through Educational Research
}

\author{
Roseanna Bourke $^{1} \cdot$ Judith Loveridge $^{2}$
}

Received: 28 May 2017/Accepted: 1 June 2017/Published online: 7 June 2017

(C) New Zealand Association for Research in Education 2017

When researchers are faced with an educational policy or practice matter that puzzles them, they often use their systematic inquiries to first understand the phenomenon at hand, and then recommend a change action for individuals, communities or systems. Researchers have particular knowledge, skills and expertise to work with other groups in society on 'wicked problems' that demand our collective attention. When the term 'wicked problem' was coined in the 1970s by Rittel and Webber (1973), they observed that once "relatively easy problems have been dealt with, we have been turning our attention to others that are much more stubborn" (p. 156). Wicked problems were viewed as complex, but not 'ethically deplorable'. Certainly, some of the contributions in this issue are dealing with stubborn, or intractable, or enduring educational issues that, on the surface at least, appear as if they should be relatively easy to solve. However when explored in greater depth through thoughtful, well-designed and conducted research, it becomes evident that entrenched beliefs, attitudes, policies or practices inhibit more considered response. In keeping with Rittel and Webber's view of the social sciences, "social problems are never solved. At best they are only re-solved-over and over again" (p. 160). The prospect of never arriving at an answer, but only at better questions to be asked of wicked educational problems is both disconcerting and reassuring. By encouraging the reader to engage with the researcher to revisit familiar education challenges in different ways, our contributors are inviting us into help make sense of, and grapple with the issues they raise, together.

In this issue, the respective authors have chosen to disseminate their research to question the status quo of policies and practices within educational organisations and systems. Some of the articles address particular policy issues in education

Roseanna Bourke

R.Bourke@massey.ac.nz

1 Institute of Education, Massey University, Palmerston North, New Zealand

2 Victoria University, Wellington, New Zealand 
which are broadly concerned with equity and the dismantling of systematic barriers to children and young people achieving their full potential, or of students participating in higher education, or of academic colleagues feeling a sense of disconnect in our own tertiary institutions. These authors are no longer satisfied that current practices, cultures, or the 'way we do things here' should go unquestioned. Their research is being actively used to help develop new and shared understandings, and to take a position on an area they feel is important to unpack and understand in richer and more complex ways. These articles represent thoughtful responses to wicked educational problems, both in terms of the authors' motivations for their research, and the wider impact their research might have on the dispositions and actions of other individuals, organisations or communities.

For many of these contributions, the use of qualitative research captures the essence of the phenomenon under investigation and delivers vivid, poignant messages. We can 'hear' the voices in Kidman and Chu, the participants' humour, frustration, observation, critique and can appreciate more about what it is to walk in the shoes of Māori and Pacific scholars caught up in neoliberal constraints of academic settings. Likewise, in Berryman and Fry's article we 'hear' the Auditor General's and Māori students' frustration at the pace and scope of change for Māori students in terms of their daily experiences in schools. We can also 'hear' the associate teachers in Sewell, Hansen and Weir's research who explore the nature of working with and mentoring student-teachers. In Shepard et al's article, both teaching staff and students within a tertiary institution articulate very clear views on what it is teach, to learn and to partner as teachers and learners, in a tertiary institution. From Cheeseman, McDonough and Golemac we also learn of the importance of listening closely to children's thinking.

Kidman and Chu have written a provocative narrative for anyone working within tertiary education institutions that serves also as a clarion call for systematic educational change. The authors interviewed Māori and Pacific senior scholars across 9 universities and Wananga in New Zealand and present some disturbing but not unexpected results - for those who experience the subtle cultural biases from within tertiary educational institutions on a daily basis. Through their interest in the role of 'scholar outsiders', Kidman and Chu explore in a novel way the familiar internal institutional expectations of being 'an academic' combined with the external demands faced by universities. This article foregrounds restrictive social and institutional expectations on Māori and Pacific senior scholar development and identity; at one point the authors note that "In general, and with only two exceptions, Māori faculty were more likely to experience intellectual, social and professional isolation in departments where there were few or no other Mäori staff". This article is an important read for researchers and faculty staff across the tertiary sector in Aotearoa New Zealand tertiary institutions; not only because we need to explore better ways together to become more biculturally aware and open to different agendas and aspirations, but to also provide support for "mounting resistance to the neoliberal 'creep' of managerialism into academic life".

Sewell, Hansen and Weir explore associate teachers' mentoring of studentteachers through their Lead Associate Teacher project using an inquiry-based methdology. They argue that being an effective teacher does not make for a skilled 
associate teacher (AT), and that often the associate teacher does not understand the element of mentoring in AT role. While Sewell et al. foreground the familiar concept of partnership between university-based ITE providers and those institutions who host student-teachers, their findings include the importance of a re-created space (hybrid space, boundary space) between the organisations as an essential tool to create new ways of thinking to 're-solve' the wicked educational problem of theory-practice divides.

Shephard and colleagues present an article co-authored by staff and students at a tertiary institution. In an action research project they explored how institutional processes might empower students to initiate change within their institution through staff-student partnerships. The article investigates how students can "lead learning in sustainability beyond the boundaries of departmental curricula". In authentic partnership style, the students were involved as colleagues on the project and some emerged as leaders. Essentially this article challenges a deeply embedded feature of higher education - the power relationship between teacher and learner. The teachers involved in this project are "convinced that a higher education that does not empower students to be responsible for their own learning is inadequately preparing them for life after university".

McPhail asks whether knowledge matters, and raises concerns that a neo-liberal environment for both schools and higher education foregrounds specific values. His article explores the tensions that arise when the curricula and pedagogy that students experience in their secondary school context is different to that experienced in the university. Using three study vignettes, McPhail argues for a renewed focus on disciplinary knowledge alongside novel pedagogical approaches that are studentcentred. He argues for the imperative in higher education "to refocus our attention on the importance of disciplinary knowledge and its interrelationship with pedagogy to bring them into a more productive alignment".

Anthony and Hunter explore grouping practices within secondary school mathematics classrooms. Their research involved teachers who use a range of approaches to group students when learning mathematics: flexible grouping, ability grouping, mixed ability grouping and no grouping. Findings from this work point to changes in teacher practice around grouping practices but the authors contend that professional learning and development is required for teachers to gain the confidence to sustain such change, as well as including targeted training in preservice teacher education. They argue that "in supporting the development of adaptive expertise associated with ambitious mathematics we need to encourage prospective teachers to examine the nature of social conditions in schools and theorise the lack of fit between some, but not all, students and the demands of mathematics education". This suggests that decisions around grouping of students are therefore a complex cultural, political and educational decision. They argue however, that 'status quo' must be challenged in an informed way.

Smardon and Charteris present a commentary on professional learning and development (PLD) in schools. Given that PLD is widely accepted as a "key policy lever for shifting practice in schools and driving philosophical change", they raise concerns about the introduction of a contestable funding model for PLD in schools, with facilitators needing to become accredited through the Ministry of Education. 
At the heart of the commentary is the concern that teacher inquiry might be materially affected by increased control of what PLD is available, and from whom.

Berryman and Fry traverse policy developments, evaluations and empirical research as they examine the vision and intent of the Ministry of Education's Māori education policy, Te Kotahitanga, and appraise the extent to which the policy has been successfully implemented. In exploring this issue, they draw on student perspectives from data that were gathered in 2001 as Te Kotahitanga was launched, and from 150 senior Māori students in 2015 who were identified as "having enjoyed and achieved education success as Māori". Whilst the authors acknowledge that some advances have been made between 2001 and 2015 in reducing the achievement disparity between Māori and non- Māori, the voices of these students who have been successful within the system reveal "disturbing echoes of the experiences of the students of 2001". Like the students in 2001, they recounted needing to overcome barriers and challenges that were not experienced by nonMāori, encountering negative stereotypes, needing to be strong in their cultural identity and being aware that many of their peers and whānau were not achieving the success that is expected from schooling. The authors argue that the message from students is that a focus on improving achievement is not enough; the transformation of how the education system performs, that was promised in the principles of Te Kotahitanga, needs to be realised "to address the education debt we owe these students". In Rittel and Weber's terms, the wicked problem of this education debt still needs to be re-solved.

McMenamin examines the way inclusive education has developed in the New Zealand education policy context. Specifically, she provides a historical analysis of developments in the 1980s and 1990s, tracing changes in both special and general education policy concerning the education of children, and also the influences of international policy developments. She argues that although the use of the language of inclusion emerged in the Special Education 2000 policy, the ideas and practices underpinning equity had been articulated in New Zealand within education and the wider social context for some time.

Gasson, Pratt, Smith and Calder locate their exploratory study concerning the impact of cost on children's participation in school-based experiences in the broader context of research examining the relationship between student achievement and socio-economic status. A web-based questionnaire was used to examine parents' perceptions about the impact of the cost of school related activities on children's engagement and participation.. Findings indicate that cost incurring school activities that are offered as optional activities "can exclude students whose families are unable or unwilling to pay". The authors argue that more research is required to ascertain whether this could be another factor contributing to the relationship between low SES background and student underachievement.

Cheeseman, McDonough and Golemac report on a study with 12 children aged 5-7 in an Australian primary school which investigated children's thinking about weighing. They observed children and had informal conversations with them, probing their thinking as the children investigated weighing using suspended balance scales, weights and a range of objects. Their findings reveal the ways that "young children can indeed think about 'big' ideas of mathematics in a natural and 
meaningful way". The authors argue for the importance of "thinking conversations" where adults listen and observe with care and question children in ways that enable them to share their thinking and competencies. They note too, the importance of activities and tools that stimulate curiosity and engage children to persist with challenges, and remind us of the "power of investigative play".

Case, Starkey, Jones, Baker-Collo and Feigin present their findings from a two phase study concerned with teachers' understanding of child mild traumatic brain injury (mTBI, commonly referred to as concussion). Children who experience mTBI may be at risk of on-going cognitive, emotional behavioural and academic problems that impact on their learning and functioning at school but research on support for children at school has tended to focus on those with severe TBI.

The articles in this issue reflect a community of researchers who are committed to solving and re-solving a myriad of problems in education in Aotearoa New Zealand. In choosing to report their systematic inquiries as they have, the researchers have enabled the diversity of participants' 'voices' to be heard. To achieve this, they have engaged in many hours of research, developing trust and respect from participants who each have their own, personal experiences of wicked educational problems and status quo thinking, and want their voice to be heard. This issue of NZJES presents a range of approaches to investigating and reporting knowledge and learning about the ways in which enduring global educational challenges are constructed and experienced in the Aotearoa New Zealand context. In reporting the educational, life and identity experiences of those affected by status quo policies and practices, researchers are encouraging us all to continue to solve and re-solve familiar but intractable educational problems, to appreciate them as complex challenges, and to keep searching for novel and productive ways of organising our inquiries.

Roseanna Bourke and Judith Loveridge

Editors

\section{Reference}

Rittel, H. W. J., \& Webber, M. M. (1973). Dilemmas in a general theory of planning. Policy Sciences, 4, 155-169. 